\title{
Juízos e valores morais: a perspectiva de investigação dos modelos organizadores do pensamento ${ }^{1}$
}

\author{
Mário Sérgio Vasconcelos ${ }^{2}$ \\ Universidade Estadual Paulista Júlio de Mesquita Filho, Assis-SP, Brasil \\ Valéria Amorin Arantes \\ Universidade de São Paulo, São Paulo-SP, Brasil \\ Leonardo Lemos de Souza \\ Universidade Federal de Mato Grosso, Rondonópolis-MT, Brasil \\ Maria Teresa Ceron Trevisol \\ Universidade do Oeste de Santa Catarina, Joaçaba-SC, Brasil \\ Maria Elvira Belloto \\ Universidade Paulista Júlio de Mesquita Filho, Assis-SP, Brasil
}

\begin{abstract}
Resumo: As ideias propostas neste estudo teórico têm como objetivo ampliar as perspectivas de investigação sobre juízos e valores morais. Após uma reflexão crítica sobre teorias que contribuíram com importantes conceitos no campo da Psicologia Moral, foram feitos alguns apontamentos que nos parecem promissores nessa área, tendo por referencial teórico-metodológico a Teoria dos Modelos Organizadores do Pensamento. Essa teoria procura destacar que apenas os recursos cognitivos operatórios não são suficientes para explicar como o sujeito apreende e julga a realidade. Nessa perspectiva, conclui-se como fundamental o papel dos conteúdos na organização das representações mentais relacionadas aos juízos e valores morais.
\end{abstract}

Palavras-chave: juízo moral, representação mental, valores, modelos organizadores.

\section{Moral judgment and values: an investigation perspective of organizing models of thinking}

\begin{abstract}
The ideas proposed on this theoretical study have as an aim to amplify the perspectives of investigation about moral judges and values. After a critical reflection about theories that contributed with important concepts in Moral Psychology field, we made some notes that we think are very hopeful in this area using as theoretical and methodological reference the Theory of Organizing Models of Thinking. This theory detaches that only the operative cognitive resources aren't enough to explain how the subject learns and judges the reality. In this perspective, we conclude as fundamental the role of the contents in the organization of mental representation related to moral judges and values.
\end{abstract}

Keywords: moral judgment, mental representation, values, organizing models.

\section{Juicios y valores morales: perspectiva de investigación de los modelos organizadores del pensamiento}

\begin{abstract}
Resumen: Las ideas propuestas en este estudio teórico visan ampliar las perspectivas de investigación sobre juicios y valores morales. Después de reflexionar críticamente sobre teorías que dieron importante contribución conceptual en el campo de la Psicologia Moral, hacemos algunas indicaciones que parecen ventajosas en el área, tomamos como referencial teórico-metodológico la Teoría de los Modelos Organizadores del Pensamiento. Esa teoría busca destacar que no sólo los recursos cognitivos operatorios son suficientes para explicar como el sujeto apreende y juzga la realidad. De esa perspectiva, concluimos, que el papel de los contenidos en la organización de las representaciones mentales relacionadas a los juicios y valores morales es fundamental.
\end{abstract}

Palabras clave: juicio moral, representación mental, valores, modelos organizadores.

No intuito de apresentar, sob a perspectiva da Teoria dos Modelos Organizadores do Pensamento, alguns pontos que nos parecem fundamentais para as investigações realizadas no campo da Psicologia Moral, dividimos nossas reflexões

\footnotetext{
1 Este texto foi revisado seguindo Acordo Ortográfico da Língua Portuguesa (1990), em vigor a partir de $1^{\circ}$ de janeiro de 2009.

2 Endereço para correspondência:

Mário Sérgio Vasconcelos. Universidade Estadual Paulista Júlio de Mesquita Filho (UNESP). Faculdade de Ciências e Letras de Assis. Departamento de Psicologia Evolutiva, Social e Escolar. Av. Dom Antonio, 2100. Assis-SP. CEP: 19.806-900. E-mail: vascon@assis.unesp.br
}

em três partes. Num primeiro momento, destacaremos discussões teórico-metodológicas pertencentes ao campo da Psicologia Moral. Enfocaremos as principais temáticas e problemas na investigação da moralidade a partir de críticas referentes às perspectivas cognitivo-evolutivas, como as de Piaget e Kohlberg. Nesse sentido, daremos destaque à Teoria dos Modelos Organizadores do Pensamento, entendendo que a investigação da moralidade está em permanente construção e tem buscado novas fontes teóricas e metodológicas para compreender a complexidade do funcionamento psicológico relacionado à moral. Num segundo momento, apresentaremos os principais conceitos da Teoria dos Modelos 
Organizadores e suas articulações com o funcionamento psicológico na elaboração de juízos, valores e ações morais. Por fim, relataremos algumas pesquisas que têm sido desenvolvidas com base nesse referencial e apontaremos aspectos que, a nosso ver, ampliam as perspectivas de investigação no estudo da moralidade.

\section{Psicologia moral: temas e conceitos revisitados}

Desde a década de 1970, tem sido grande o interesse da comunidade científica pelo tema da moralidade humana. Esse interesse pode ser observado, em vários países, pela expressiva produção de artigos e livros sobre o assunto (Pérez-Delgado \& Garcia-Roz, 1991). No Brasil, levantamento bibliográfico feito por Vasconcelos e Lemos-de-Souza (2004), também aponta para uma grande variedade de temas investigados na área. De um modo geral, os marcos interpretativos dessas investigações partem, principalmente, dos referenciais teóricos elaborados por Jean Piaget e/ou Lawrence Kohlberg (La Taille, 1998; Lepre \& Martins, 2009; Macedo, 1996). Tais referenciais abordam a moralidade por meio da perspectiva cognitiva, descrevendo os processos conscientes envolvidos no desenvolvimento do raciocínio moral em seus aspectos estruturais e evolutivos.

Não há dúvida de que no campo de investigações psicológicas sobre o desenvolvimento moral, Piaget (1932/1994) foi pioneiro e inovador com suas ideias apresentadas no livro O Juízo Moral na Criança. Partindo do pressuposto de que "toda moral é um sistema de regras e a essência de toda moralidade consiste no respeito que o indivíduo sente por tais regras" (Piaget, 1932/1994, p.7), estudou crianças em situação de jogos e submetidas à análise de histórias hipotéticas buscando compreender, por meio do método clínico, a evolução da tomada de consciência do respeito pelas regras e os julgamentos morais. Os resultados de suas investigações possibilitaram a formulação de uma teoria psicogenética interacionista do desenvolvimento moral que indica tendências evolutivas estruturais caracterizadas pelos estágios pré-moral (anomia), de moralidade heterônoma (heteronomia) e de moralidade autônoma (autonomia). As constatações de Piaget (1932/1994) ainda hoje servem de referência para estudos produzidos em vários países.

Kohlberg (1992), autor dos mais difundidos nessa área de investigação, ampliou ideias de Piaget (1932/1994) sobre a psicogênese da moral e, nesse campo, foi radical no aprofundamento da vertente evolutiva estruturalista. Desenvolveu toda uma teoria sobre o raciocínio moral em adolescentes e adultos baseando-se em estudos sobre dilemas morais a serem resolvidos, envolvendo situações que conflitavam a obediência às normas estabelecidas com o atendimento a uma necessidade humana situacional. Os resultados de seus estudos indicaram seis estágios de julgamento moral: orientação pela obediência e punição; orientação ingenuamente egoísta; orientação do tipo "bom menino"; orientação para manter a autoridade e a ordem social; orientação do tipo contratual legalista e orientação por consciência lógica por princípios universalizantes (Bzuneck, 1975). Tais estágios foram agrupados em três níveis: pré-moral ou pré-convencional; convencional; e pós-convencional. Para Kohlberg (1992), esses níveis são universais, mas as possibilidades de sua construção dependem das interações das pessoas com o seu meio.

Os pressupostos das teorias de Piaget (1932/1994) e Kohlberg (1992) sobre o desenvolvimento moral foram e têm sido alvos de debates. As críticas, de certo modo, buscam refletir sobre o conceito de moralidade, apontando para uma compreensão mais complexa dos juízos e dos valores morais no campo psicológico. Gilligan (1993), por exemplo, a partir de estudos realizados com homens e mulheres de diferentes idades, elaborou suas críticas referindo-se ao fato de Kohlberg (1992), assim como Piaget (1932/1994), ter realizado suas pesquisas sob a ótica da moralidade masculina (caracterizada pela moral a partir do ideal de justiça e regida pela racionalidade). Para Gilligan (1993), esses autores desprezaram particularidades de uma moral feminina baseada na ética do cuidado (care), que inclui, entre outros aspectos, as necessidades afetivas. Essas duas orientações da moralidade humana (masculina e feminina) não podem ser vistas, segundo a autora, como divergentes, mas sim como complementares. Na perspectiva de Gilligan (1993), a moral estaria fortemente marcada pela cultura que, ao estabelecer modelos de relações de gênero, influenciaria a produção de valores e de julgamentos baseados em princípios diferenciados entre homens e mulheres. Autores como Campbell e Christopher (1996) consideram que Gilligan (1993) contribuiu para a rediscussão dos paradigmas que orientaram até então o tema da moralidade, não só por introduzir a "ética do cuidado", mas também por considerar as necessidades do eu, ou self, relacionadas à afetividade.

Outra vertente teórica que se destacou nesse campo da psicologia envolve a moral pró-social. Estudos nessa perspectiva começaram a ganhar notoriedade na investigação da moralidade humana com os trabalhos de Nancy EisenbergBerg (1979) sobre a evolução dos raciocínios de crianças e adolescentes expostos a dilemas que envolviam ações prósociais. Até então, havia um predomínio de investigações sobre os raciocínios morais a respeito de comportamentos indesejáveis (transgressões), como faziam, por exemplo, os estudos baseados nas ideias de Kohlberg (1992).

Embora haja diferenças entre os autores que estudam a moral pró-social, existe, de maneira geral, um consenso de que os raciocínios e comportamentos pró-sociais são os de caráter altruísta (Araújo, 1998). São comportamentos e raciocínios que levam em consideração sempre as necessidades e o bem-estar dos outros em detrimento das necessidades e do bem-estar do próprio sujeito. Nessa vertente, as ações e os raciocínios voltados para as necessidades do outro são considerados essenciais para a manutenção da coletividade e da harmonia social. Segundo Araújo (1998), tais pressupostos trazem elementos da perspectiva kantiana sobre a moral e são fundamentados nos deveres e na primazia da razão sobre as emoções. 
Campbell e Chistopher (1996) também apontam a presença de pressupostos kantianos nas teorias pró-sociais e, a esse respeito, formulam críticas pelo fato de as teorias prósociais considerarem: (a) a razão como único elemento que funciona efetivamente como regulador moral; (b) o formalismo como ponto estrutural essencial na moralidade e (c) o altruísmo como a moral "centrada" no outro. Segundo esses autores, o racionalismo e o formalismo kantiano relegam outros conteúdos envolvidos nos raciocínios e nas ações morais, desconsiderando aspectos como, por exemplo, fatores concretos envolvidos num contexto, variáveis culturais presentes no momento de decisões, afetos, justificativas morais e atribuições de valores aos comportamentos e aos pensamentos. Para Campbell e Chistopher (1996), tais exclusões "artificializam" o conceito de moral.

Buscando superar tal artificialismo presente no estudo da moral, Campbell e Christopher (1996) propuseram a valorização da perspectiva aristotélica de moral (eudemonista), na qual a felicidade é a finalidade. Isso denota uma ampliação nos aspectos envolvidos: a moral pode ser referendada na felicidade do outro, bem como na felicidade do eu. Os questionamentos sobre a perspectiva kantiana, notadamente o racionalismo, levaram esses autores a problematizar, também, a redução do desenvolvimento moral à esfera do desenvolvimento cognitivo, tal como proposto na perspectiva cognitivo-evolutiva de Kohlberg (1992). Relevaram, como vimos, a proposta de ampliação dos fatores psicológicos envolvidos na moralidade (como por exemplo, os afetos), bem como a de outros temas morais a serem estudados, além da justiça, como as várias virtudes, os princípios morais baseados na felicidade, no bem e no cuidado.

A partir destas críticas, as relações entre ação e juízo moral também se tornam objeto de discussão (Martins, 2003; Araújo, 1998). Destacam-se os conteúdos como reguladores morais, já que os recursos operatórios (estruturas) nem sempre dão conta de explicar por que um sujeito com níveis altos de desenvolvimento moral (na perspectiva de Kohlberg (1992), por exemplo) não age da maneira como julga uma situação. Isso também implica num redimensionamento do entendimento da moralidade humana inserindo, dentre esses conteúdos, as emoções, os sentimentos (como a vergonha), as virtudes e as relações destes com o self. Tais aspectos são considerados relevantes na explicação de juízos e ações morais.

Desse modo, podemos afirmar que ideias como as de Carol Gilligan (1993), as teorias pró-sociais e os estudos de Campbell e Christopher (1996) auxiliaram no redimensionamento do objeto da moral, principalmente por apontarem para a complexidade do fenômeno.

A nosso ver, são promissoras as perspectivas de análise que procuram destacar a complexidade que envolve a construção da moralidade. As regularidades e diversidade de elementos envolvidos apontam para a necessidade de perspectivas teóricas e metodológicas de investigação que dêem destaque ao sujeito psicológico em seus aspectos funcionais e estruturais e aos conteúdos que compõem o raciocínio moral. Nessa direção encontra-se a Teoria dos Modelos Organizadores do Pensamento, elaborada por Montserrat Moreno Marimón, Genoveva Sastre Vilarrasa, Aurora Leal e Magali Bovet (Moreno Marimón, Sastre Vilarrasa, Bovet, \& Leal, 2000), que considera, em seus pressupostos, além dos recursos operatórios, a importância dos conteúdos na formulação de raciocínios morais. Modelos organizadores do pensamento são representações que explicitam o papel dos conteúdos abstraídos e atribuídos como significativos pelo sujeito na construção da realidade e de si mesmo. Tais conteúdos são conhecimentos sociais, culturais e pessoais (valores, leis, normas, regras, sanções e convenções), bem como os sentimentos e as emoções. Os conteúdos (e suas relações) oferecem várias possibilidades que compõem a complexidade do real e a partir deles o sujeito pode dar sentido às suas experiências.

Considerando a amplitude e especificidade de tais pressupostos, detalharemos os conceitos envolvidos nesse referencial teórico-metodológico.

\section{Modelos organizadores: contribuições para a investigação da moralidade}

A busca de explicações científicas baseadas na complexidade é uma das intenções da proposta da Teoria dos Modelos Organizadores do Pensamento. Vários fenômenos psicológicos, notadamente os da cognição, historicamente foram estudados quase que exclusivamente pela via da regularidade e da simplicidade, sendo considerados, às vezes, como naturais. No entanto, como sugere Moreno Marimón e cols. (2000, p. 16):

Em psicologia, o descobrimento de constantes é o que permite abordar o estudo da diversidade, que adquire sentido graças à sua referência a tais constantes. Uma vez descrita a regularidade, o pensamento voltase para a diversidade; o imutável deixa de ser o centro de nossos interesses e buscamos as explicações na mudança. A idéia de mudança penetra também a psicologia quando começa a observar o ser humano como um ser que evolui. Mas em toda mudança há algo que permanece, e a conjunção da permanência e da mudança aumenta a complexidade dos novos fenômenos que se vislumbram, surgindo a necessidade de modelos capazes de descrever e interpretar simultaneamente o que permanece e o que muda, isto é, capazes de dar conta da complexidade.

Moreno Marimón e cols. (2000) anunciam, valendo-se dessas considerações, a necessidade da elaboração de uma teoria que explique e dê conta das variações no pensamento do sujeito e das mudanças que se constituem na complexidade dos procedimentos que a mente humana utiliza para construir e se apropriar do conhecimento. Esse pensamento 
complexo estaria mais "próximo da realidade", mas ainda não seria a própria realidade senão uma interpretação dela, resultando em recortes da realidade. A ideia de complexidade no pensamento busca a integração dos diversos aspectos que compõem essa realidade, especialmente a presença de recursos operatórios, de conteúdos e representações na construção do conhecimento.

Com essa perspectiva, a Teoria dos Modelos Organizadores se propõe a discutir o papel das estruturas e conteúdos no modo como o sujeito pensa a realidade, já que apenas os recursos operatórios não são suficientes para explicar o funcionamento psicológico moral. Incluem-se, nas operações empregadas, os valores, os sentimentos, os princípios e as regras envolvidos no juízo e na ação moral. É um modo de explorar o funcionamento da cognição, na sua dupla composição: estruturas e conteúdos (Lemos-de-Souza, 2009).

A ideia de modelo organizador fundamenta-se em estudos da Psicologia Cognitiva e da Psicologia Genética. Moreno Marimón e cols. (2000) destacam, respectivamente, as contribuições teóricas de Johnson-Laird (1983) sobre os modelos mentais, e as reflexões de Piaget (1977) sobre a psicogênese do conhecimento.

Para Piaget (1977), o desenvolvimento cognitivo ocorre pela construção de estruturas de pensamento que vão modificando-se por meio dos processos de assimilação e acomodação resultantes das interações do organismo (sujeito) com o mundo (físico e social). As estruturas são sistemas de organização da realidade, construídas e utilizadas pelo sujeito para a apropriação do real. À medida que o sujeito constrói novas estruturas, há uma ampliação das condições de pensamento e de ação. Nesse sentido, comparado a um espiral ascendente, o nível de estruturação do real pelo sujeito, se amplia em termos de abrangência e extensão.

Embora para Piaget (1977), nesse processo majorante, forma e conteúdo sejam indissociáveis e interdependentes, não há dúvida de que os conteúdos não se constituíram em seu principal foco de investigação: o destaque esteve concentrado na forma (estruturas, organização e funcionamento localizados no sujeito). No entanto, do ponto de vista da Teoria dos Modelos Organizadores, Moreno Marimón e cols. (2000) afirmam que os conteúdos envolvidos na situação influenciam sobremaneira quando o sujeito procura construir uma explicação de um determinado fenômeno. As autoras fundamentam esta afirmação alegando que os experimentos de Piaget (1977) e seus colaboradores demonstraram que existem defasagens no desenvolvimento das estruturas operatórias. Isso quer dizer que muitos sujeitos, que conseguem aplicar uma determinada estrutura para solucionar/explicar um problema com o qual se deparam, podem não conseguir utilizá-la em situações isomorfas. Fato semelhante acontece no campo da moralidade, por exemplo, quando Kohlberg (1992) encontrou sujeitos que, para algumas situações, respondem de maneira convencional e, para outras, de maneira pós-convencional. Kohlberg (1992) considerou as descontinuidades como anomalias, explicando-as, no caso de adolescentes, como parte da crise ocasionada por essa fase de transformações biopsicossociais.

Tais descontinuidades ou anomalias são, para Moreno Marimón e cols. (2000, p. 75), "mais que a exceção, parecem ser a norma no funcionamento cognitivo". Crítica semelhante foi feita por Murphy e Gilligan (1980) sobre as defasagens dos estágios morais em adolescentes e adultos entrevistados por Kohlberg (1992) em suas pesquisas. Moreno Morimón e cols. (2000) destacam a importância da presença dos conteúdos nas defasagens do desenvolvimento cognitivo, explicando que estruturas e conteúdos são componentes interdependentes nesse processo. As estruturas atuam sobre a realidade procurando apropriar-se dela; o conteúdo compõe essa realidade e acaba também por ser um possibilitador da mudança de estrutura, exigindo a criação de outras mais adequadas a ele.

As contribuições de Johnson-Laird (1983) estão voltadas para as definições de modelos mentais e sua funcionalidade. Para o autor, modelos mentais são representações internas da realidade exterior, que se constituem em sistemas organizados para representá-la. Investigando modelos mentais elaborados por sujeitos diante de problemas enunciados verbalmente, esse autor concluiu que, para alguns conteúdos, os sujeitos não conseguem, em seu raciocínio, utilizar a lógica operatória formal. Quando submetidos a outros conteúdos que suscitam o mesmo caminho do experimento anterior para a resolução do problema, percebeu que os sujeitos conseguem resolvê-lo mesmo sem dominarem a lógica operatória formal. Assim, de uma situação concreta, a lógica formal pode não extrair conclusões, sendo necessário um princípio extra lógico: os conteúdos, a partir dos quais o sujeito possa extrair conclusões e realizar suposições. Essa situação concreta tem uma organização que dá forma aos modelos mentais que se localizam na estrutura semântica da situação.

Moreno Marimón e cols. (2000) ressaltam que os resultados dos experimentos de Johnson-Laird (1983) se referem às estruturas semânticas e que, para o autor, as representações mentais são elaboradas a partir dessas estruturas vinculadas a situações e conteúdos na compreensão de uma simulação da realidade. Nessa perspectiva, o ponto de partida de um modelo está fora do sujeito, dando condições para a estruturação do pensamento. A atividade do sujeito aqui é a de "elaborar" esses modelos, compreendendo os significados da situação, e raciocinar sobre eles, isto é, manipular os modelos elaborados. Com essas proposições, Johnson-Laird (1983) afirma que uma teoria da inferência - uma teoria que explique como o sujeito chega a sistemas de explicações sobre a realidade -, não é possível somente com base no estudo das operações lógico-formais no sujeito.

A discussão proposta por Johnson-Laird (1983) e Piaget (1977) refere-se às relações nos processos cognitivos, entre o declarativo (representações) e o procedural (operações). Piaget (1977) considera que o procedural "informa" o declarativo e os cognitivistas como Johnson-Laird (1983) afirmam que o declarativo "informa" o procedural. Aparentemente, 
essas relações separam esses processos, tornando-os independentes. No entanto, essa suposta distinção e independência não existem entre os conteúdos e a forma nos raciocínios elaborados pelos sujeitos.

Enfim, a proposta da Teoria dos Modelos Organizadores é uma teoria complementar à piagetiana e às ideias de Jonhson-Laird (1983) e se propõe a elaborar uma síntese, buscando desvelar o papel e a função dos conteúdos na atividade cognitiva. $\mathrm{O}$ foco é entender a atividade cognitiva a partir dos elementos considerados significativos pelo sujeito numa determinada situação concreta e considerar que a organização desses elementos não depende, exclusivamente, de recursos operatórios; mais frequentemente depende dos conteúdos. Como o sujeito tende à organização desses conteúdos, as estruturas operatórias (lógico-matemáticas) são também fundamentais para as implicações (ou relações) dos conteúdos envolvidos, oferecendo poder de explicação e resolução dos acontecimentos e situações de conflitos.

\section{Os componentes de um modelo organizador}

Para Moreno Marimón e cols. (2000), um modelo organizador pode ser descrito a partir de duas ideias básicas: (a) são modelos de realidade; e (b) são construídos pelo sujeito no processo de apropriação do conhecimento. São modelos de realidade porque se constituem produto da representação da realidade de fato elaborada pelo sujeito. O termo "realidade" utilizado pelas autoras ressalta a diferença que elas fazem de realidade objetiva e subjetiva. A primeira é aquela que serve de referência aos modelos organizadores, e a segunda é o que o sujeito compreende da primeira.

Um modelo organizador é elaborado na interação do sujeito com o meio, que atua como um regulador da atividade cognitiva. O sujeito - ativo nesse processo - abstrai os dados de uma situação concreta e atribui-lhes significados e uma função, desse modo, constrói um modelo organizador para explicar a situação. Assim, um modelo organizador é definido como:

[...] o conjunto de representações que o sujeito realiza a partir de uma situação determinada, constituído pelos elementos que abstrai e retém como significativos entre todos os possíveis, aqueles que imagina ou infere como necessários, os significados e as implicações que lhes atribui, e as relações que estabelece entre todos eles. Os modelos organizadores do pensamento constituem aquilo que é tido por cada sujeito como a realidade, a partir da qual elabora pautas de conduta, explicações ou teorias (Sastre Vilarrasa, Moreno Morimón, \& Fernandez, 1994, p. 19) (tradução nossa).

Os resultados das interpretações que o sujeito realiza dos fatos ou dos objetos perceptíveis são os elementos de um modelo organizador. Esses elementos, por sua vez, são produto de uma atividade interpretativa feita pelo próprio sujeito sobre a realidade, que tem sua origem: (a) nas abstrações dos observáveis; (b) nas inferências sobre a situação com as quais se depara ou, ainda; (c) na invenção de outros elementos, em função da necessidade de compreensão da situação observada (Moreno Marimón e cols., 2000, p. 79).

O contexto de experiência do sujeito é fundamental na realização do processo de retenção de elementos de uma situação observada. Não são todos os elementos possíveis a respeito da situação que são eleitos; somente aqueles que têm sentido ou aos quais são atribuídos significados em função da própria experiência do sujeito. Isto também não quer dizer que o sujeito desconheça os outros elementos da situação, somente que não são considerados como representativos dela. Os elementos que não existem na realidade (produto de inferências e de invenções) têm a mesma qualidade dos considerados reais, pois fazem parte da condição de compreensão e estruturação do real desse sujeito. Desse modo, "o processo de abstração de um elemento traz consigo a sua significação, definindo a função do mesmo dentro do modelo organizador" (Moreno Marimón e cols., 2000, p. 91). Contudo, o processo de explicação de fatos da realidade também tem implicações.

As implicações, relações entre significados e elementos, são decorrências do processo de abstração. Como modelos de uma realidade representada, os modelos organizadores servem de explicação para ações; contém implicações. A realidade subjetiva do sujeito é expressa pelos modelos organizadores e constitui a base de suas explicações e ações diante dos fenômenos e dos problemas que enfrenta no cotidiano.

Os modelos organizadores não cumprem só a função de servir de base para a explicação de alguns fatos; servem também de ponto de partida para a ação, já que esta não tem como base a realidade, mas o que cada um acredita que é a realidade; dessa forma, nossas convicções guiam nossos atos mais que os fatos objetivos, o que equivale a dizer que construímos modelos da realidade (Moreno Marimón e cols., 2000, p. 91).

As implicações dos significados atribuídos aos elementos decorrem de um processo organizador e as relações entre elementos, significados e implicações retratam o modelo e sua complexidade; indicam a diversidade e as regularidades presentes na "realidade" elaborada pelo sujeito.

No campo dos conflitos morais, o sujeito psicológico, imerso num complexo de variáveis, constrói modelos organizadores buscando integrar elementos, significações e implicações (relações) envolvidas nesses conflitos.

\section{Desvelando modelos organizadores}

Para ilustrar o processo de elaboração de Modelos Organizadores, que requer um tratamento fino e pormenorizado dos dados de pesquisa, escolhemos o estudo realizado por 
Araújo (2000), cujo principal objetivo foi identificar e analisar as possíveis relações entre os estados emocionais e os modelos organizadores aplicados na resolução de um conflito moral ocorrido num contexto escolar. A autora escolheu um caminho metodológico no qual a amostra ( 90 professores e professoras de uma escola pública brasileira) foi dividida em três grupos distintos, cada um deles induzido a "vivenciar" um determinado estado emocional, antes de lhes ser solicitada a análise do conflito. Um grupo foi induzido a vivenciar estados emocionais positivos (boas lembranças), outro grupo a vivenciar estados emocionais negativos (más lembranças) e o terceiro foi denominado de grupo "neutro" porque os sujeitos não foram induzidos a vivenciar nenhum estado emocional específico. A fim de proporcionar aos sujeitos uma situação que os remetessem à reflexão sobre a própria conduta em situações de natureza moral, lhes foi apresentado um conflito em torno de uma temática que está presente no cotidiano escolar: o consumo de drogas por parte dos estudantes.

O instrumento utilizado (ver instrumento completo em Araújo, 2000), elaborado com base em uma situação real, retrata um conflito vivenciado por uma docente que flagrou um aluno fumando maconha no horário de aula. Junto a um texto que retratou essa situação, onze questões foram apresentadas aos sujeitos por escrito que, anonimamente, responderam também por escrito. Em função do tipo de análise realizada (com grande quantidade de informações para cada uma das respostas), e pelo pouco espaço disponível em um artigo, deter-nos-emos à descrição do processo de análise de apenas uma das perguntas, a saber: Coloquese no lugar da professora e tente imaginar como ela vive essa situação. Descreva detalhadamente seus sentimentos, desejos e pensamentos.

A seguir, apresentamos cada um dos passos seguidos nesse processo:

$1^{\circ}$ Passo: Identificação dos elementos abstraídos e retidos como significativos: cada uma das respostas dos sujeitos foi analisada, a fim de identificar os elementos que compuseram a organização dada por eles à situação analisada. No total, foram identificados oito elementos centrais: comportamento do aluno; sentimentos da professora; papel da professora; denunciar o fato; meio social; papel das pessoas para quem o caso deveria ser encaminhado; imagem da professora; imagem das pessoas para quem o caso deveria ser encaminhado.

$2^{\circ}$ Passo: Identificação de todos os significados atribuídos a cada um dos elementos: foi realizado um levantamento de todos os significados atribuídos a cada um dos elementos mencionados no item anterior. A seguir, apresentamos cada um desses elementos com seus respectivos significados:

- Comportamento do aluno: problemático; provoca sentimentos negativos (entre os quais medo) na professora; prejudica o aluno; causa sentimentos negativos à professora; requer ajuda; requer ajuda de pessoas preparadas; requer diálogo; requer orientação; requer solução.
- Sentimentos da professora: diferentes sentimentos negativos (impotência; medo; ansiedade; decepção; desespero; indignação; preocupação; pena; surpresa; tristeza, culpa, constrangimento, raiva, insegurança; dor; desgaste; malestar, dentre outros) levando-a a se calar.

- Papel da professora: denunciar o caso; encaminhar o caso; conversar com o aluno; ajudá-lo; orientá-lo; auxiliá-lo; recuperá-lo.

- O ato de denunciar o fato: ação que pode trazer represálias; violência; perigo.

- Meio social: violento; agressivo; perigoso.

- Papel das pessoas para quem o caso deve ser encaminha$d o$ : solucionar o problema; ajudar o aluno.

- Imagem da professora: não está preparada para ajudar o aluno; com limitações para fazê-lo.

- Imagem das pessoas para quem o caso deve ser encaminhado: estão preparadas para ajudar o aluno.

$3^{\circ}$ Passo: Implicações estabelecidas pelos sujeitos: realizou-se um levantamento das diferentes implicações estabelecidas pelos sujeitos. Nessa etapa, foram identificados quatro grandes blocos de respostas, a saber: (a) respostas que sugerem que a professora inibiria sua atuação; (b) respostas que defendem que a professora deveria encaminhar o caso para outras pessoas (pais, psicólogos, diretora); (c) respostas que defendem que a professora deveria orientar o aluno, dentro de suas possibilidades, e recorrer a pessoas melhor preparadas para que possam fazê-lo; (d) respostas que defendem que a professora deveria atuar para ajudar o aluno.

$4^{\circ}$ Passo: Elaboração dos Modelos Organizadores do Pensamento: considerando os procedimentos adotados anteriormente (para identificação dos elementos, significados e implicações), foi realizada uma análise intrapessoal, ou seja, analisou-se a resposta de cada um dos sujeitos separadamente (em função dos elementos abstraídos, dos significados e das implicações/relações estabelecidas entre eles), o que nos permitiu identificar quatro diferentes modelos organizadores (Modelos 1, 2, 3 e 4), os quais se encontram a seguir descritos.

Modelo 1: O elemento organizador deste modelo são os sentimentos da professora que, além de serem significados atribuídos como impotência e medo, levam-na a se calar, ou seja, impedem a professora de tomar uma atitude diante do problema. Além dos sentimentos da protagonista, os sujeitos que aplicaram este primeiro modelo abstraíram os seguintes elementos: comportamento do aluno, papel da professora; o ato de denunciar o fato e o meio social. Embora o papel da professora seja significado como o de denunciar o caso, ao entenderem que o comportamento do aluno causa medo na protagonista, que o meio social é perigoso e que a denúncia pode lhe trazer represálias, violência ou perigo, os sujeitos que recorreram a esse modelo justificam que, por medo, a professora inibiria sua atuação. Vejamos um exemplo que ilustra o Modelo 1: 
Sente-se impotente, incapaz de tomar uma atitude mais rígida. Qualquer atitude mais séria poderá acarretar em danos à sua pessoa. Sabe-se lá o que o aluno seria capaz de fazer para que seus pais não soubessem do vício... seria seguro para a professora denunciar ou seria melhor se omitir? Em seu lugar não saberia qual atitude seria mais sensata.

Modelo 2: O elemento organizador deste modelo é o papel da professora que, neste caso, recebe como único significado o ato de encaminhar o problema, característica principal do modelo 2. O comportamento do aluno é visto como um problema que requer solução e o papel das pessoas para quem o problema será encaminhado é, por sua vez, o de solucioná-lo. Identificamos, também, como elemento abstraído, neste modelo, o sentimento de preocupação da professora. A seguir, um exemplo de resposta que ilustra o Modelo 2:

Eu iria ficar muito preocupada, pois é uma situação muito delicada, mas não teria outra atitude a tomar se não informar a diretoria em seguida aos pais do aluno para que eles solucionassem o caso.

Modelo 3: Neste modelo o comportamento do aluno foi significado como um comportamento que solicita ajuda de pessoas preparadas e a imagem da professora como alguém que não está muito preparada para ajudar o aluno. Com isso, aqueles que recorreram a esse modelo consideraram não somente a atuação da protagonista na situação-problema, mas também a de outras pessoas, a quem atribuem mais preparo para ajudar o aluno. Os sentimentos da professora foram assim significados: impotência, insegurança, tristeza e dor. Todo o conjunto de elementos, significados e implicações que constituem o terceiro modelo levam os sujeitos a formularem respostas como a que se segue:

Acredito que ela deva ter se sentido impotente, pois era um aluno sem problemas aparentes e todos gostavam dele. Eu, no lugar dela, não saberia o que fazer, eu tentaria procurar alguém ou alguma coisa que eu pudesse fazer para ajudá-lo.

Modelo 4: Neste modelo organizador identificamos três elementos abstraídos e retidos como significativos: o comportamento do aluno, os sentimentos da professora e o papel desta. O conjunto destes elementos, com seus diferentes significados, levam os sujeitos a sugerirem que a protagonista atuaria para ajudar o aluno. Apesar de atribuírem significados diferentes aos sentimentos (sempre negativos) da protagonista - constrangimento; culpa; desgaste; decepção; mal-estar; impotência; raiva; tristeza; ansiedade -, sinalizam seu desejo em ajudá-lo. Desse modo, deduzem que, além de causar sentimentos negativos na professora, tal comportamento requer ajuda, orientação, diálogo:
Eu amo meus alunos de uma forma geral. Quando estou com eles, mesmo em detrimento (sic) ao curso tempo que ficamos juntos, tento conhecer um pouco mais (o máximo possível) da personalidade de cada um. A 'pessoa', o 'ser humano'. No lugar da professora, em primeiro lugar, morreria de dó da criança, e mesmo sabendo que estaria diante de um problema quase impossível de ser tratado, esquematizaria uma forma de chegar e achegar-me a ele. Gradativamente eu tentaria ganhar sua confiança e provocaria a conversa. Eu poderia abordar o assunto de várias formas: começando por passar um filme relativo ao problema para a classe do aluno. Eu iria entrar em contato com ele de qualquer jeito.

Após elaboração dos modelos organizadores, foi realizada uma análise quantitativa, em função dos referidos modelos e da variável "estado emocional" (positivos, negativos e "neutro"). Tal análise permitiu à autora concluir que o estado emocional das pessoas exerce grande influência na maneira como organizam seu pensamento e, consequentemente, como resolvem seus conflitos de natureza moral: dos 30 sujeitos do grupo positivo, 28 deles aplicaram modelos organizadores 3 e 4 , ou seja, defenderam a ideia de que a professora deveria atuar para ajudar o aluno (apenas dois sujeitos aplicaram modelos 1 e 2); dos 30 sujeitos do grupo negativo, 21 deles aplicaram modelos 1 e 2, sugerindo que a professora deveria calar-se ou encaminhar o caso a terceiros (apenas nove sujeitos aplicaram modelos 3 e 4); os 30 sujeitos que compuseram o grupo "neutro", se dividiram igualmente entre os modelos 1 e 2 (15 deles aplicaram esses modelos) e os modelos 3 e 4 (15 sujeitos também).

Entre os resultados encontrados na pesquisa, destaca-se o fato de que vivenciar emoções positivas implica em uma maior possibilidade de os sujeitos situarem a conduta do protagonista em um universo que não gera contradições entre seus desejos e seus deveres. Assim, estes sujeitos mantêm uma grande coerência na forma de organizar seu raciocínio, tanto na perspectiva deontológica, quanto na perspectiva cognitivo-afetiva (Araújo, 2000).

Para além dos resultados (qualitativos e quantitativos), essa pesquisa trouxe uma nova perspectiva de estudo sobre o papel das emoções e sentimentos na relação com os aspectos cognitivos, pois não se limitou a estudar a atribuição de sentimentos dos personagens, mas, também, como os sentimentos e as emoções podem influenciar no próprio modo de organizar os pensamentos.

\section{Estudos sobre a moralidade com base na teoria dos Modelos Organizadores do Pensamento}

A maioria dos estudos que se utilizam do referencial teórico-metodológico dos Modelos Organizadores tem utilizado o trabalho de leitura coletiva do material, nos quais um grupo de pesquisadores discute, em cada resposta dada 
pelo participante, os elementos abstraídos, os significados atribuídos e as implicações/relações entre elementos e significados. Valendo-se desse material são definidos os modelos organizadores, isto é, o conjunto de representações que o participante produziu e utilizou para apreender ou solucionar o problema sugerido. Assim, na análise, consideram-se as estratégias cognitivas produzidas pelos participantes e quais as dimensões que se destacam nessas estratégias, quaisquer que sejam elas - valores, sentimentos, objetos, histórias.

O processo de construção dos modelos leva em consideração a subjetividade dos próprios pesquisadores envolvidos. Longe de se pretender uma teoria e estratégia de investigação sobre o funcionamento psíquico que se baseia na neutralidade, a própria Teoria dos Modelos Organizadores considera o pesquisador como um sujeito que também constrói conhecimento sobre o real e sobre si mesmo. As relações entre elementos e significados que o pesquisador produz, baseado em uma dada situação, constituem um processo fundamentado na interação com seu objeto de conhecimento.

Por isso, a proposta da Teoria dos Modelos não é criar categorias prévias e fixas de análise. As contribuições dos estudos com essa perspectiva sobre a moralidade avançam quando rompem com a análise baseada exclusivamente nos estágios, que apontam, predominantemente, as estruturas lógicas envolvidas na avaliação e solução do conflito moral. Desse modo, o modelo organizador, como unidade de análise do funcionamento psíquico, é um sistema aberto, não sendo definido somente pela estrutura.

Feitas essas considerações, parece-nos relevante mencionar outros estudos que se valeram dos pressupostos dos Modelos Organizadores do Pensamento para investigarem a moralidade humana.

No Brasil destacam-se as pesquisas de Affonso (2008), Lemos-de-Souza (2008a, 2008b), Lemos-de-Souza e Vasconcelos (2003), Martins (2003, 2008), Pátaro (2007), Stach-Haertel (2009), Trevisol (2002, 2003) e Vasconcelos, Bellotto e Endo (2007). Outros estudos também foram publicados no Brasil, mas realizados no exterior, como os de Araújo (2000), Sastre Vilarrasa e Moreno Marimón (2000) e Sastre Vilarrasa e Timon Herrero (2003). Há também estudos desenvolvidos e publicados na Espanha por Pavón (2002), Sastre Vilarrasa, Moreno Marimón e Fernandez (1994) e Sastre Vilarrasa, Moreno Marimón e Pavón (2001).

De um modo geral, esses estudos podem ser reunidos em três grupos: (a) dedicam-se a investigar o papel organizativo dos estados emocionais e dos sentimentos nas relações entre juízos e ações morais (Araújo, 2000, 2003; Araújo \& Sastre Vilarrasa, 2003, 2005; Martins, 2003); (b) estão voltados para a complexidade de juízos morais elaborados em função dos conteúdos envolvidos em conflitos (princípios morais de justiça, felicidade, cuidado), numa perspectiva psicogenética ou não (Lemos-de-Souza, 2008a; Lemos-de-Souza \& Vasconcelos, 2003; Pávon, 2002; Sastre Vilarrasa \& Moreno Marimón, 2000; Sastre Vilarrasa, Moreno Marimón, \& Fernández, 1994; Sastre Vilarrasa \& Timon Herrero, 2003); (c) investigam as mudanças de modelos em função de diferentes idades a partir de problemas morais ou de conhecimento social (Sastre Vilarrasa, Moreno Marimón, \& Pávon, 2001; Trevisol, 2002; Vasconcelos, Bellotto, \& Endo, 2007).

No primeiro grupo, podemos destacar o trabalho, já descrito anteriormente de Araújo (2000) cujo objetivo principal foi identificar e analisar as possíveis relações entre os estados emocionais e os modelos organizadores aplicados na resolução de um conflito moral vivenciado em ambientes escolares.

No segundo grupo podemos mencionar o trabalho de Lemos-de-Souza (2008a) que se propôs a investigar os modelos organizadores de 400 jovens de 15 a 21 anos, de ambos os sexos, na resolução de conflitos interpessoais na escola, a partir de uma perspectiva de gênero. O autor utilizou como instrumento uma situação que envolvia a discriminação sexual e de gênero nas relações entre meninos e meninas na escola - a homofobia. As questões feitas após a situação referiam-se aos pensamentos, sentimentos e ao dever dos protagonistas da discriminação (quem a presencia e quem a sofre).

Levando-se em consideração as respostas dos participantes sobre as questões do/da protagonista que presencia a discriminação, pôde-se evidenciar que as representações de gênero configuraram diferentes modelos organizadores para se resolver o conflito interpessoal. Assim, os modelos atribuídos às meninas foram diferentes daqueles atribuídos aos meninos na situação. Desse modo, os resultados demonstraram que os jovens e as jovens participantes interpretaram a situação a partir do sexo das protagonistas da situação. Os modelos organizadores construídos pelos participantes apontaram proximidades e distanciamentos em relação à cultura androcêntrica e heterossexista. Eles se referiam às relações de amizade, ao direito de ser, à vergonha e à preservação da identidade sexual e de gênero, ao cuidado com quem sofre a discriminação e à decepção para com os amigos e amigas que realizam a discriminação. São produtos da interpretação do sujeito sobre o conteúdo (gênero e sexualidade) presente na situação, o que destaca a complexidade da vida cotidiana como fonte de referências para o funcionamento psíquico de interpretação da realidade. Isso aponta, segundo o autor, para uma relação estreita entre as representações de gênero e a elaboração de decisões morais e éticas. As dimensões morais e éticas presentes demonstram articulação com a ética da justiça e a do cuidado; trazem à tona sentimentos e valores envolvidos na relação eu/outro diante do conflito interpessoal.

No terceiro grupo, destacamos o estudo realizado por Trevisol (2002), que pesquisou como crianças entre oito e 14 anos organizam e julgam, a partir de uma história, uma faceta do conhecimento social: os direitos das crianças. Os resultados obtidos confirmam a premissa de que a compreensão de um determinado conteúdo social representa uma atividade de significação e ressignificação desses conteúdos pelo sujeito. A partir da análise efetuada sobre os raciocínios dos sujeitos, Trevisol (2002) identificou uma 
diversidade de modelos organizadores. Cada uma dessas organizações mentais representa uma determinada forma de pensar o conteúdo social dos direitos das crianças. Embora não tenha encontrado diferenças significativas na aplicação dos modelos em relação às idades, a autora verificou que o lugar de análise que o sujeito se coloca para efetuar a leitura da realidade representa um fator importante na significação e no julgamento de determinado contexto, na organização dos elementos, significados e implicações que compõem os modelos organizadores de pensamento. Esse lugar representa um marco diferencial na forma como ele compreende e significa os acontecimentos. A autora considera esse fator relevante visto que sua amostra consistiu de sujeitos que não vivenciaram em seu cotidiano a ausência da garantia de seus direitos. Não há vivência e significação desse conteúdo, logo os elementos considerados para avaliá-lo são representativos do que estes sujeitos conseguiram organizar a partir do que ouviram, leram ou tomaram conhecimento por outras vias de acesso ao conhecimento. Os argumentos utilizados para se posicionar diante da história apresentada constituem mais uma reprodução de um discurso do que a subsunção do que essa parcela de realidade ou de problema representa para o sujeito.

Também nesse terceiro grupo, podemos citar a pesquisa de Vasconcelos, Bellotto e Endo (2007), que objetivou identificar significações abstraídas por alunos de $2^{\mathrm{a}}$ e $4^{\mathrm{a}}$ série do ensino fundamental sobre a indisciplina em sala de aula. Para atingir tais objetivos, os autores investigaram os modelos organizadores abstraídos por 40 participantes; 20 alunos da $2^{\mathrm{a}}$ série e 20 alunos da $4^{\mathrm{a}}$ série, de ambos os sexos, pertencentes a uma escola pública. Como instrumentos de pesquisa utilizaram, principalmente, a entrevista e a apresentação de dois conflitos hipotéticos relacionados a situações de indisciplina em sala de aula. Com o intuito de elucidar os modelos organizadores de pensamento, analisaram as respostas empregadas pelos sujeitos destacando os elementos, os significados e as implicações entre elementos e significados. A análise dos dados indicou principalmente que: (a) a quase totalidade dos participantes, direta ou indiretamente, desaprova os atos "indisciplinados" retratados nos conflitos e (b) são frequentes as ações dirigidas no sentido de evitar a incidência do ato "indisciplinado", identificados majoritariamente nos modelos apresentados por alunos da $4^{\mathrm{a}}$ série. Já os relatos das entrevistas apontaram que atos indisciplinados aparecem mais entre os alunos (as) da $4^{\mathrm{a}}$ série. Tais resultados levaram os autores a concluírem, dentre outros fatores, que os modelos abstraídos por ambos os grupos $\left(2^{\mathrm{a}}\right.$ e $4^{\mathrm{a}}$ série $)$ revelaram regularidades e diversidade nos raciocínios presentes na resolução dos conflitos e que a variedade de modelos organizadores identificados evidencia a importância dos conteúdos afetivos e socioculturais na construção dos argumentos relacionados aos julgamentos morais. Além disso, os resultados dessa investigação ressaltam a necessidade de se desenvolver estudos mais aprofundados sobre as discrepâncias entre valores e ações morais.
Outros trabalhos, como os de Araújo (2000), Pavón (2002) e Sastre Vilarrasa e Moreno Marimón (2000) concluíram que a Teoria dos Modelos Organizadores tem contribuído para a compreensão da relação entre afetividade e cognição no âmbito da moralidade, bem como para o entendimento de tipos de raciocínio utilizados pelos sujeitos na resolução de conflitos morais, por permitir a visualização dos conteúdos utilizados. Araújo (1999), que também se utilizou dessa teoria, ressalta a possibilidade de compreensão do funcionamento da moral de maneira integrada, isto é, levando em consideração os diversos conteúdos (os valores, os sentimentos e as demais características do self) nos raciocínios e nas ações morais.

\section{Considerações finais}

Após a análise da quase totalidade dos trabalhos que trazem como referencial teórico-metodológico a Teoria dos Modelos Organizadores, podemos afirmar que essa perspectiva nos pareceu promissora pelos seguintes motivos:

(a) expressa, no estudo do fenômeno psicológico, a organização entre elementos, significados e suas implicações;

(b) possibilita explorar a conjugação entre estrutura e conteúdos, permitindo assim uma apreensão mais abrangente da complexidade do modo como o sujeito pensa a realidade, já que apenas os recursos operatórios não são suficientes para explicar o funcionamento cognitivo - incluem-se nas operações empregadas valores, sentimentos, princípios e regras envolvidos nos raciocínios;

(c) permite observar a diversidade de modelos de realidade;

(d) permite observar as regularidades entre modelos de realidade;

(e) não estabelece, numa investigação, a classificação prévia das respostas dos sujeitos, desse modo, confere uma melhor fidedignidade aos dados coletados, demonstrando com mais detalhes seu papel no funcionamento psíquico;

(f) no campo da psicologia, representa uma alternativa metodológica significativa na análise de conteúdos;

(g) no campo da moralidade avança, notadamente, na análise de situações envolvendo conflitos.

Finalmente, cabe destacar que os apontamentos feitos nesse ensaio apontam para a necessidade de ampliação dos referenciais teórico-metodológicos para o estudo dos juízos, valores e ações morais. Para que possamos compreender melhor a complexidade psicológica dos seres humanos é preciso desvelar o conceito de juízo moral para além do modelo estrutural em vigor na Psicologia, explorando mais profundamente as relações entre aspectos funcionais, estruturais e conteúdos.

\section{Referências}

Affonso, S. B. (2008). Estados emocionais e modelos organizadores do pensamento: Um estudo sobre violência de gênero. Tese de doutorado não-publicada, Faculdade de Educação, Universidade Estadual de Campinas, Campinas. 
Araújo, U. F. (1998). O sentimento de vergonha como regulador moral. Tese de doutorado, Instituto de Psicologia, Universidade de São Paulo, São Paulo.

Araújo, U. F. (1999). Conto de escola. São Paulo: Moderna. Araújo, V. A. A. (2000). Cognição, afetividade e moralidade. Educação e Pesquisa, 26(2), 137-153.

Araújo, V.A.A. (2003). Afetividade, cognição e moralidade na perspectiva dos modelos organizadores do pensamento. In V. A. Arantes (Org.), Afetividade na escola: Alternativas teóricas e práticas (pp.109-128). São Paulo: Summus.

Araújo, V. A. A., \& Sastre Vilarrasa, G. (2003). Moralidad, Sentimientos y Educación. Educar, 31, 47-66.

Araújo, V. A. A., \& Sastre Vilarrasa, G. (2005). A. Individual appropriation of thoughts from shared feelings. In First ISCAR Congress International Society for Cultural and Activity Research, $1^{\text {st }}$ (Vol. 1, pp. 480-481). Sevilha, Espanha.

Bzuneck, J. A. (1975). Desenvolvimento moral: Avaliação dos estágios Kohlbergianos em crianças e adolescentes de Londrina. Dissertação de mestrado não-publicada, Instituto de Psicologia, Universidade de São Paulo, São Paulo.

Campbell, R. L., \& Christopher, J. C. (1996). Moral development theory: A critique of these kantian presuppositions. Development Review, 16, 1-47.

Eisenberg-Berg, N. (1979). Development of children's prosocial moral. Developmental Psychology, 15, 128-137.

Gilligan, C. (1993). Uma voz diferente: Psicologia da diferença entre homens e mulheres da infância à idade adulta (C. Nathanael \& C. Caixeiro, Trads.). Rio de Janeiro: Rosa dos Ventos.

Johnson-Laird, P. M. (1983) Mental models: Towards a cognitive science of language, inference and consciousness. New York: Cambridge Press.

Kohlberg, L. (1992). Psicologia del desarrollo moral. Bilbao: Desclée.

La Taille, Y. (1998). Prefácio à edição Brasileira. In J. M. Puig, A construção da personalidade moral (pp. 7-15). São Paulo: Ática.

Lemos-de-Souza, L. (2009). Modelos organizadores, sujeito e educação: Considerações a partir do pensamento complexo. Ciências \& Cognição, 14, 283-291.

Lemos-De-Souza, L. (2008a). Modelos organizadores, gênero e moral na resolução de conflitos entre jovens na escola. Tese de doutorado não-publicada, Faculdade de Educação, Universidade Estadual de Campinas, Campinas.

Lemos-De-Souza, L. (2008b). Representações de gênero e diversidade na escola: Um estudo com crianças, jovens $e$ educadores. Pesquisa em andamento cadastrada na Próreitoria de Pesquisa (Propeq), Universidade Federal de Mato Grosso, Rondonópolis, MT.

Lemos-De-Souza, L., \& Vasconcelos, M. S. (2003). Modelos organizadores do pensamento: Uma perspectiva de pesquisa sobre o raciocínio moral de adolescentes autores de infração. Psicologia em Estudo, 8(2), 45-59.
Lepre, R. M., \& Martins, R. A. (2009). Raciocínio moral e uso abusivo de bebidas alcoólicas por adolescentes. Paidéia(Ribeirão Preto), 19, 39-45.

Macedo, L. (Org.). (1996). Cinco estudos de educação moral. São Paulo: Casa do Psicólogo.

Martins, S. P. (2003). Juízo e representação da ação moral: Um estudo a partir da teoria dos modelos organizadores do pensamento. Dissertação de mestrado não-publicada, Faculdade de Educação, Universidade Estadual de Campinas, Campinas.

Martins, S. P. (2008) Cultura e gênero: Um estudo na perspectiva dos modelos organizadores do pensamento. Tese de doutorado não-publicada, Faculdade de Educação, Universidade Estadual de Campinas, Campinas.

Moreno Marimón, M., Sastre Vilarrasa, G., Bovet, M., \& Leal. A. (2000). Conhecimento e mudança: Os modelos organizadores na construção do conhecimento. Campinas: Unicamp.

Murphy, J. M., \& Gilligan, C. (1980). Moral development in late adolescence and adulthood: A critique and reconstruction of Kohlberg's theory. Human Development, 23, 77-104.

Pátaro, C. S. O. (2007). Pensamento, crenças e complexidade humana. Ciências \& Cognição, 12, 134-149.

Pavón, T. (2002). Modelos organizadores y razionamiento moral: El sentimiento de culpa. Tese de doutorado, Faculdade de Psicologia, Universidade de Barcelona, Barcelona, Espanha.

Perez-Delgado, E., \& Garcia-Ros, R. (1991). La Psicologia del desarrollo moral. Madrid, Espanha: Siglo Veintiuno de España.

Piaget, J. (1994). O juízo moral na criança. São Paulo: Summus. (Original publicado em 1932)

Piaget, J. (1977). Recherches sur l'abstraction réfléchissante. Paris: Presses Universitaires de France.

Sastre Vilarrasa, G., \& Moreno Marimón, M. (2000). Nuevas perspectivas sobre el razionamiento moral. Educação $e$ Pesquisa, 26, 123-135.

Sastre Vilarrasa, G., \& Tímon Herrero, M. (2003). Los sentimientos en el ámbito de la moral. Educação $e$ Pesquisa, 29, 219-234.

Sastre Vilarrasa, G., Moreno Marimón, M., \& Fernandez, T. (1994). El derecho de ser y la autorrenuncia. Los modelos organizadores en la preadolescencia. Educación y Sociedad, 27-28, 55- 67.

Sastre Vilarrasa, G., Moreno Marimón, M., \& Pavón, T. (2001). Cultura de género y diversidad en el desarrollo moral. Educar, 22-23, 141- 153.

Stach-Haertel, B. U. (2009). A constituição de subjetividades legitimadoras de desigualdades de gênero: Um estudo a partir de referenciais da Psicologia e da Educação. Dissertação de mestrado não-publicada, Faculdade de Educação, Universidade de São Paulo, São Paulo.

Trevisol, M. T. C. (2002). A construção do conhecimento social: Um estudo dos modelos organizadores do pensamento em sujeitos entre 8 e 14 anos. Tese de doutorado não- publicada, Instituto de Psicologia, Universidade de São Paulo, São Paulo. 
Trevisol, M. T. C. (2003). Os direitos das crianças vistos pelas próprias crianças: Um estudo sobre a compreensão de sujeitos que freqüentam o Programa de Erradicação do Trabalho Infantil (PETI). Relatório de Pesquisa, Universidade do Oeste de Santa Catarina, Joaçaba, SC.

Vasconcelos, M. S., Bellotto, M. E., \& Endo, K. H. (2007). Significações abstraídas por alunos de $2^{a}$ e $4^{a}$ série do ensino fundamental sobre a indisciplina em sala de aula. Relatório de Pesquisa, Faculdade de Ciências e Letras, Universidade Estadual Paulista/CONE, Assis, SP.

Vasconcelos, M. S., \& Lemos-de-Souza, L. (2004). Tendências e perspectivas do construtivismo. Revista Vertentes, 7(1), 33-48.

Mário Sérgio Vasconcelos é Professor Associado da Universidade Estadual Paulista Júlio de Mesquita Filho, campus de Assis.

Valéria Amorin Arantes é Professora Doutora da Faculdade de Educação da Universidade de São Paulo.

Leonardo Lemos de Souza é Professor Adjunto do Instituto de Ciências Humanas e Sociais da Universidade Federal do Mato Grosso, campus de Rondonópolis.

Maria Teresa Ceron Trevisol é Professora Doutora do Programa de Mestrado em Educação da Universidade do Oeste de Santa Catarina, campus de Joaçaba.

Maria Elvira Bellotto é Professora Assistente da Universidade Estadual Paulista Júlio de Mesquita Filho, campus de Assis.

Recebido: 05/05/2009

$1^{a}$ Revisão: 09/10/2009

$2^{a}$ Revisão: 15/11/2009

Aceite final: 14/01/2010 